Artículo de reflexión derivado de investigación
Revista Colombiana de Educación, N. 69 Segundo semestre de 2015 , Bogotá, Colombia.

\section{La construcción de la demanda educativa en los pueblos originarios del sureste mexicano}

//The Construction of Demands for

Education among Indigenous Peoples

from Southeastern Mexico

\section{//A construção da demanda educativa \\ nos povos originários do sudeste \\ mexicano}

Bruno Baronnet* Evaluado: 12/02/2015
Recibido: 19/12/2014 06/04/2015

\begin{abstract}
Doctor en Sociología, Colegio de México, Universidad de París - Sorbonne Nouvelle. Profesor e investigador en Educación Intercultural en el Instituto de Investigaciones en Educación de la Universidad Veracruzana. Veracruz, México. bruno.baronnet@gmail.com
\end{abstract}

\section{Resumen}

Este artículo analiza procesos de construcción social que estructuran las demandas de educación en las Cañadas de Ocosingo de la Selva Lacandona, al sureste de Chiapas en México. Las relaciones entre actores educativos y comunidades de campesinos, principalmente tseltales, están marcadas desde la aparición de la escuela en el siglo XX por un contexto organizativo de negociación y confrontación con el Estado, en el cual ocurren procesos de politización de las identidades étnicas y la apropiación social de la educación escolar. En las condiciones dadas por el conflicto político, los pueblos mayas generan y extienden experiencias novedosas de escuelas comunitarias, desde el final de los años ochenta y en las dos últimas décadas, de acuerdo con prácticas renovadas de autogobierno que dan sentido a un proyecto alternativo asumido como propio y autónomo.

A partir de métodos de investigación socio-antropológica, etnografías y entrevistas, el artículo estudia la generación de prácticas educativas autonómicas en una región multicultural en conflicto, cuyos territorios están reorganizados a veinte años de la creación de nuevos municipios por el zapatismo. Además, en las dos décadas que preceden el surgimiento de las escuelas del movimiento zapatista, la demanda de educación se construye asimismo en relación con la autoorganización campesina en lucha por la dignidad de las culturas mayas. Las actuales prácticas alternativas se presentan como producto de políticas educativas autoadministradas por actores indígenas incrustados en estructuras de poder comunal y regional que son desconocidas y excluidas en el marco de las políticas nacionales de educación.

\section{Abstract}

This article analyses processes of social construction that shape the demands for education in the Cañadas (canyons) of Ocosingo, in the Lacandon Jungle, south-eastern Chiapas in Mexico. The relations among educational actors and peasant communities, mainly Tseltales, are marked since the emergence of schools in the twentieth century by an organizational context of negotiation and confrontation with the State, involving processes of politicization of ethnic identities and social appropriation of school education. Under the conditions created by political conflict, the Maya peoples have generated and extended new experiences of community schools since the end of the 80s and over the last two decades, in accordance with renewed practices of self-government that give meaning to an alternative project that they have assumed as their own autonomous undertaking.

\section{Palabras clave}

Educación intercultural, autonomía, pueblos originarios, Chiapas, México

\section{Keywords}

Intercultural education, autonomy, indigenous peoples, Chiapas, Mexico

\section{Palavras chave}

Educação intercultural, autonomia, povos originários, Chiapas, México 
Based on socio-anthropological research methods, ethnographies and interviews, the article studies the generation of autonomous educational practices in a multicultural region in conflict, whose territories are reorganized twenty years after the creation of new municipalities by the Zapatistas. Moreover, in the two decades preceding the emergence of the Zapatista movement's schools, the demand for education is also constructed in relation to self-organizing peasants struggling for the dignity of the Mayan cultures. The current alternative practices are presented as a product of self-managed educational policies by indigenous actors, embedded in structures of communal and regional power that are unrecognized and excluded within the framework of national education policies.

\section{Resumo}

Este artigo analisa os processos de construção social que estruturam as demandas de educação em Las Cañadas de Ocosingo de la Selva Lacandona, al sudeste de Chiapas no México. As relações entre atores educativos e comunidades de camponeses, principalmente Tseltales, estão marcadas desde a aparição da escola no século XX por um contexto organizativo de negociação e confrontação com o Estado, no qual ocorrem processo de politização das identidades étnicas e a apropriação social da educação escolar. Nas condições dadas pelo conflito político, os povos Maias geram e estendem experiências inovadoras de escolas comunitárias, desde o final dos anos oitenta e nas duas últimas décadas de acordo com práticas renovadas de autogoverno que dão sentido a um projeto alternativo assumido como próprio e autônomo.

A partir de métodos de pesquisa sócio-antropológica, etnografias e entrevistas, o artigo estuda a geração de práticas educativas autonômicas em uma região multicultural em conflito, cujos territórios estão reorganizados vinte anos depois da criação de novas municipalidades estabelecidas pelo zapatismo. Além disso, nas duas décadas que antecedem o surgimento das escolas do movimento zapatista, a demanda da educação constrói-se assim mesma em relação à auto-organização camponesa em luta pela dignidade das culturas Maias. As atuais práticas alternativas apresentam-se como produto das políticas educativas auto-administradas pelos atores indígenas incrustados em estruturas de poder comunal e regional que são desconhecidas e excluídas no marco das políticas nacionais de educação.

La historia reciente de la expansión de la escuela en territorios indígenas de América Latina encuentra una ilustración sugerente en las experiencias comunitarias de la Selva Lacandona en Chiapas, México. En la segunda mitad del siglo XX, la construcción social de las demandas en educación de los pueblos originarios en las Cañadas de Ocosingo corresponde a un contexto político de relación conflictiva con el Estado, en el cual los procesos de socialización política generan condiciones favorables para alternativas educativas interculturales de acuerdo con prácticas de autogobierno. En complejas condiciones de organización y politización de las identidades religiosas y étnicas, pero también de represión política y cultural, entre 1974 y 1993 se gestaron prácticas educativas que luego harían frente a la política nacional neo-indigenista. Luego de la irrupción del Ejército Zapatista 
de Liberación Nacional (EZLN), se reconstruyeron las demandas de escuelas dignas y de "buen nivel" en el momento en que su manejo comunitario se constituía en una amplia alternativa educativa administrada por actores y estructuras de poder comunal y regional.

¿En qué sentido las Cañadas representan el escenario de la constitución de demandas y proyectos propios que giran hacia otra educación, autónoma, "verdadera" e intercultural crítica, sentando las bases decoloniales para una pedagogía alternativa? Se busca comprender cómo se manifiesta la construcción social de demandas autonómicas en el contexto de la generación endógena de políticas comunales de educación, que representan asimismo el producto de la influencia y la acción de los movimientos sociales e indígenas en el sector educativo, pedagógico y cultural. Los procesos sociales de construcción de la demanda educativa se definen desde una dimensión socio-antropológica como prácticas creadas, objetivadas o institucionalizadas a nivel político-cultural. Junto a la reivindicación lingüística, estas demandas pueden llegar a convertirse en un componente significativo del movimiento indígena (Gros, 2000, p. 155), pues en diferentes partes de América Latina a finales de los años ochenta ya la cuestión educativa en aéreas de población indígena formaba parte de la agenda política al lado de otras demandas como la cuestión agraria, lo que suponía del Estado una respuesta política que se puede notar en apariencia en los cambios sustanciales de los planteamientos oficiales sobre educación intercultural en la casi totalidad de los países de la región (pp. 172-175). Para analizar estas implicancias en términos sociales, este artículo aborda primero la trayectoria histórica de la llegada tardía y precaria de la escuela a la Selva Lacandona, antes de detenerse en la cuestión de la educación y socialización política en las Cañadas de Ocosingo. Después se revisan algunos retos derivados del nombramiento comunitario del educador campesino e indígena, así como de la relación tensa que entretejen los pueblos originarios con el Estado acerca del tema sensible de la gestión inter e intracomunitaria de los asuntos pedagógicos en la esfera local y regional. Si consideramos que el carácter intercultural de cualquier currículo escolar se define a partir de estrategias etnopolíticas que dan sentido a un proyecto educativo situado en determinadas condiciones, entonces la educación intercultural propia se construye social e históricamente en el contexto estructurante del autogobierno indígena, evitando dejar el manejo de los asuntos educativos en manos del Estado y sus agentes, que no son aceptados ni considerados como legítimos. La transformación curricular y la apropiación social de la escuela dependen de las condiciones autonómicas, lo que significa que la autonomía política se vuelve una condición para el ejercicio de una educación intercultural crítica 
que incluya valores, saberes y aspiraciones legítimas de los pueblos. Siguiendo a C. Walsh (2010, p. 88), la interculturalidad crítica en la educación parte del problema del poder, su patrón de racialización y la diferencia colonial que ha sido construida en función de ello, es decir que se define como "una construcción de y desde la gente que ha sufrido un histórico sometimiento y subalternización", a la imagen de muchos territorios indígenas de Latinoamérica como las regiones mayas del sureste mexicano.

\section{La incidencia de las comunidades originarias en la escuela}

Considerando la capacidad de apropiarse y controlar la organización administrativa y curricular de los asuntos escolares en sus territorios, la incidencia de los pueblos mayas de Chiapas en la gestión educativa merece una breve puesta en perspectiva histórica para el análisis social. Aún en el siglo XX, la construcción y la existencia misma de las escuelas dependía de la disposición del hacendado y de la voluntad de los habitantes de cada localidad, mientras que con la federalización educativa los municipios perdieron progresivamente funciones, como la posibilidad de proponer, solventar y remover a maestros (Rockwell, 2007 y Lewis, 2005). En los primeros años posteriores a la Revolución mexicana, se abrió una época de cambios favorables para la autonomía de las comunidades originarias en algunos estados del país, para que estas participaran e incidieran en la selección y la vigilancia de los maestros. Es común observar que los recursos públicos destinados a la educación suelen ser menores en los lugares donde se asignan los educadores con menos experiencia, menor preparación y retribución, y con poca oportunidad y disponibilidad para integrarse a la comunidad política y la vida cultural de la localidad.

En las Cañadas y el norte de la selva de Chiapas, la llegada precaria de la escuela primaria siguió el movimiento de nuevos asentamientos ejidales en la segunda mitad del siglo XX, en un contexto también de conflictividad social en torno a los asuntos de la tenencia de la tierra (Bobrow-Strain, 2007). Las iniciativas de apertura de cursos comunitarios por parte de los comuneros representan los antecedentes de la implantación del sistema de enseñanza controlado a partir de los años setenta por el Estado federal, a través de modalidades mono y bilingües. Por ejemplo, miembros de distintas generaciones de campesinos tseltales recuerdan a menudo que gran parte de los adultos de edad avanzada aprendieron a leer y 
escribir con maestros reclutados en la región y en la ciudad de Ocosingo, pagados por los jefes de familia y a veces por los hacendados. Todo parece indicar que no fueron pocos los maestros (y algunas maestras) "particulares" y "municipales" que enseñaron hasta la década de los años setenta, en escuelas construidas por los campesinos en "tierras nacionales" o prestadas por el terrateniente. El reclutamiento comunitario de los maestros en esa época no tan remota sugiere también transformaciones con respecto al origen étnico y el rol de activista político-cultural que desempeñan los educadores comunitarios vinculados a las organizaciones campesinas. Estas transformaciones conducen a alimentar la emergencia de propuestas pedagógicas capaces de aprovechar el contexto cultural, lingüístico y organizativo de los pueblos y que caracterizan la generación endógena de demandas educativas socialmente construidas.

A lo largo de las últimas décadas, se evidencia el refuerzo de las demandas indígenas de Chiapas por acceder a un mayor control comunitario (e intercomunitario) sobre la organización de las escuelas en sus territorios, así como sobre el desempeño del docente y la misión educativa en general. Sin embargo, las luchas educativas del movimiento indígena en gestación en México en los años setenta, no reivindican de manera abierta la ampliación de márgenes de autonomía local en la gestión administrativa y pedagógica de sus escuelas, ya que esto no forma parte de los discursos de las organizaciones implantadas con poder de convocatoria en las regiones indígenas. Antes del fin de los años ochenta, los primeros brotes de luchas y movimientos indígenas en México tampoco evidencian demandas de autonomía educativa (Sarmiento y Mejía, 1987). No obstante, la aparición de los primeros "maestros campesinos" entre 1988 y 1989 comprueba que surgen prácticas político-educativas que tienden a ser participativas, autogestivas y ligadas a las estrategias sociales étnicas y campesinas. Además, la gestión escolar comunitaria no se limita ahora a experimentaciones aisladas y locales, sino que opera en redes intermunicipales a su vez adheridas a proyectos políticos regionales.

El acceso real de los niños a una educación bilingüe y culturalmente pertinente no está ausente del proceso de construcción de un movimiento social indígena que desconfía de la figura moderna del docente federal u "oficial", que no comparte la pertenencia social al grupo comunitario. El Congreso Indígena de 1974 en San Cristóbal de Las Casas aporta un antecedente mayor a la reprobación campesina e indígena de la política educativa indigenista. Representantes de las comunidades tseltales recalcan que el maestro "es una persona ladina que viene de la ciudad con diferente cultura, se cree superior a nosotros y no respeta nuestra manera de ser; abusan de nuestra ignorancia". Los delegados invocan su derecho a 
tener docentes que sepan, respeten y enseñen el idioma y las costumbres. "No queremos que sean comerciantes. No queremos que se emborrachen. No queremos que den mal ejemplo [...], que sean flojos. Queremos que estén entregados al servicio de la comunidad [...], que haya un comité independiente de los maestros, elegido por la comunidad para que vigile el trabajo del maestro" (Congreso Indígena, 1974).

A la imagen de contextos comparables como en el Cauca, Colombia, donde el sector educativo es el espacio también de construcción de demandas y estrategias específicas por parte de los actores políticos indígenas (Baronnet, 2013), el crecimiento del sistema nacional de educación indígena en las Cañadas atraviesa contradicciones de naturaleza social y estructural. Entre estas se destaca la dificultad del Estado para reclutar y formar maestros provenientes de los nuevos asentamientos de campesinos tseltales formados en cooperativas ejidales en la segunda parte del siglo Xx. Prevalece cierta reticencia por parte del magisterio rural y bilingüe para someterse a trabajar en las rudas condiciones de vida de la Selva Lacandona, lo que explica en parte la permanente rotación e inestabilidad del personal docente (los Ilamados "maestros mochila-veloz"), que cuenta en general con una experiencia y una motivación limitadas.

En los años ochenta y noventa, el Estado mexicano buscó completar la cobertura de la educación primaria en los poblados más pequeños y aislados gracias a las modalidades de educación "comunitaria" y "compensatoria", mediante jóvenes semiprofesionales que usaban materiales diseñados específicamente para el trabajo multigrado (Rockwell, 1997). Como se detallará más adelante en el artículo, se trata primero de la aparición en 1988 de las escuelas de la modalidad "primaria indígena estatal" originada en el Programa de Educación Integral de las Cañadas de la Selva Lacandona (Peicasel), ahora ampliado en el Proyecto Educador Comunitario Indígena (PECI), y que proviene del impulso de la organización Unión de Uniones Ejidales constituida en la Asociación Rural de Interés Colectivo (ARIC-UU). A partir del periodo 1994-1995 se establecieron las escuelas comunitarias del Proyecto de Atención Educativa a la Población Indígena del Consejo Nacional de Fomento Educativo (Conafe). La normatividad federal las obligaba a reclutar jóvenes, principalmente varones, tseltales menores de 20 años en general, y egresados de escuelas secundarias (sobre todo "telesecundarias") de localidades del municipio de Ocosingo y de sus alrededores. 
A pesar de las consecuencias directas del levantamiento zapatista sobre la dinámica de la acción pública para el crecimiento de la educación básica en estos territorios multiétnicos, se siguen encontrando en el siglo XXI (aunque en menor proporción) varias escuelas monolingües en rancherías y ejidos con población totalmente hablante de variantes dialectales del Maya-Tseltal (batsil kop), por exigencia local cuando no es por resignación. En vez de ser considerada como una riqueza, la diversidad lingüística en la escuela se vuelve un obstáculo para la intercomprensión, lo que favorece el desplazamiento lingüístico y la castellanización, pero también el distanciamiento entre los actores del magisterio y los del campesinado. Además de actuar como un "ejército de ocupación" en la comunidad, siguiendo la imagen empleada por el antropólogo Benjamín Maldonado (2002), pocos integrantes del magisterio se inclinan a hacer suyas las demandas de autonomía indígena. Desde el inicio de la difusión de la educación federal bilingüe en las Cañadas del sureste de Chiapas, la gran mayoría de los maestros en las Cañadas de la Selva son hablantes de la variante alteña de Oxchuk, lo que no permite una comunicación cómoda entre los docentes, los alumnos y sus familias. Muchos de ellos aspiran a ser propietarios de una casa en Ocosingo, de un vehículo personal y obtener un cambio de plaza cerca del centro urbano. Sin embargo, la búsqueda de una alternativa al maestro ajeno y ausentista, o "mochila veloz", se encuentra en la génesis del surgimiento contemporáneo de la educación comunitaria, más autónoma e intercultural, que surge en el contexto de la formación política e ideológica de los campesinos indígenas. Los cambios socioeducativos que se analizan en adelante son producto de la necesidad local de encontrar cómo autogenerar prácticas pedagógicas que faciliten el aprendizaje de conocimientos, valores y normas sociales que tienen sentido y pertinencia desde la perspectiva de los propios actores del movimiento.

\section{Politización de las identidades étnicas en el movimiento campesino}

En los proyectos de educación a los que aspiran las organizaciones de los pueblos originarios que politizan su identidad étnica, la lengua y la cultura son elementos primordiales que les permiten objetivar (y construir) una frontera étnica y territorial, y reclamar un cierto nivel de autonomía (Gros, 2000, p. 197). En los procesos de politización de los actores del movimiento indígena, "la identidad pasa a desempeñar el papel de una brújula que posiciona al grupo y sus miembros en mapas cognitivos (u horizontes) colectivamente construidos" (Cardoso de Oliveira, 1990, p. 146). Las identidades politizadas corresponden a la valorización de aspectos 
intersubjetivos que vuelven a dar sentido al ser indígena, ser campesino/a, pertenecer a una localidad, una religión y un grupo político. Entre las características que permiten distinguir los esfuerzos de los pueblos tseltales en la construcción de un poder educativo autónomo, se recalca el modo de organización política que los respalda y su relación con el Estado, así como la politización de las identidades étnicas, además de la capacidad de movilizar varias formas de recursos internos y externos a sus territorios (Baronnet, 2012).

En el contexto de la represión a las luchas armadas en los años setenta, nuevos actores políticos intervinieron en el escenario local de las Cañadas de la Selva: los representantes de la Iglesia inspirados por la teología de la liberación india y, pronto, miembros de organizaciones revolucionarias de diversas obediencias. Antes del levantamiento armado de 1994, con la Unión de Uniones de Ejidos "éramos el estado de las Cañadas" en palabras de Carmen Legorreta ${ }^{1}$, ex asesora política de la ARIC-UU en el tema agrario y la negociación de compra de tierras, ahora reocupadas por las bases sociales del EZLN. Formados ideológicamente en distintas luchas estudiantiles desde 1968, no pocos han sido los jóvenes militantes revolucionarios mexicanos que han valorado el potencial de transformación social del campesinado, cuya identidad indígena no ha sido el objeto de politización deliberada en un primer momento. Los actores blanco-mestizos responsables de la formación política de las bases campesinas contribuyen a construir un nuevo imaginario social y político en las Cañadas de la Selva Lacandona, como producto de la hibridación y resignificación de las identidades étnicas, religiosas, políticas y campesinas.

Aunque sea muy marginal el número de activistas de origen urbano que se acercan en distintos momentos a las autoridades campesinas e indígenas, ellos desempeñan con el tiempo prácticas de alfabetización, de educación y de movilización política mediante consultas, talleres y charlas. Por ejemplo, al final del año 1994, el Subcomandante Marcos relata en entrevista videograbada que su llegada a las montañas del sureste mexicano es "un accidente", "algo fortuito" en 1983. 
En realidad, yo llegaba aquí a dar clases, porque sabía leer y escribir y sabía de historia, de historia en general, pero, además de historia de México. Necesitaban a alguien que alfabetizara y al mismo tiempo diera historia de México. Porque los compañeros del primer grupo guerrillero [...] reclamaban también lo que ellos Ilamaban la palabra política: la historia. La historia de este país, la historia de la lucha. Entonces Ilego yo con este trabajo. (Citado en Gilly, Subcomandante Marcos \& Ginzburg, 1995, pp. 129-132)

Las primeras acciones de organización, alfabetización y concientización se insertan en los campos político y religioso, y son motivadas por la formación de cuadros. Los comuneros tseltales relatan, a veces con detalle, quiénes han estado llevando a cabo este tipo de trabajo esporádico de instrucción y movilización, antes y después del alzamiento zapatista, y reconocen que pocas veces eran maestros convencionales. En raras ocasiones, los docentes ajenos a la comunidad son considerados como "compañeros" de confianza, es decir reconocidos como legítimos para encabezar procesos de socialización política de la niñez y el acompañamiento a la formación política de los adultos.

Tanto la enseñanza escolar como la formación política de los jóvenes y adultos se realiza de manera multilingüe pero con una predominancia del castellano, aunque la situación ha mostrado una tendencia al cambio a partir de los años noventa, con el fomento del uso oral y la lectoescritura en lengua originaria en nuevos espacios políticos, especialmente desde organizaciones cercanas a la Diócesis, como la Organización Civil las Abejas, en los Altos tsotsiles (Orozco, 2014). Fuera de estos ámbitos, el uso de la lengua escrita sigue casi inexistente por la falta de documentos impresos en las variantes del tseltal, aparte de textos bíblicos en la variante de bachajón. Sin embargo, la apropiación social de la escuela es concomitante con las demandas sociales crecientes. Por consiguiente, es probable que en las Cañadas tseltales de Ocosingo los avances en el uso de la lengua escrita durante la segunda mitad del siglo XX se debieran más a los efectos de los movimientos religiosos, sociales y políticos que a la educación formal (Rockwell, 2006). La reticencia de los maestros normalistas a trasladarse a trabajar en las Cañadas, la lucha por la tierra y la nueva evangelización católica son factores que impulsaron el uso de la escritura fuera del aula ( $p$. 67). Para los actores involucrados en los procesos de construcción de la demanda educativa en el sureste mexicano, el papel de las lenguas 
originarias en la educación adquiere a menudo una gran importancia, en especial cuando ellos buscan responsabilizarse de su posible revitalización, con la ilusión de que las escuelas puedan contribuir a frenar los desplazamientos lingüísticos.

Para el sacerdote dominico Pablo Iribarren, la concepción según la cual es "la comunidad que es la responsable de la educación de sus hijos, que se hace cargo de ella", corresponde con el plan originado por Martha Orantes -su coordinadora principal como asesora de la ARIC-UU- que se han apropiado los pueblos de las Cañadas. "El maestro campesino se integra a la unión o integración de todos los elementos políticos, sociales, étnicos en la cual el cemento religioso es la clave de la unidad de su pueblo". También, comenta haber visto cómo los educadores durante el oficio en idioma tseltal traen como "ofertorio" durante la Eucaristía sus libros, cuadernos, lápices, y papeles, tal como el agente ejidal presenta sus documentos agrarios o el promotor de salud aporta jeringas y medicamentos (entrevista personal, enero 2007).

El equipo pastoral de la orden de los dominicos de Ocosingo, en ciertas ocasiones, utiliza el mecanismo de consulta a cada comunidad eclesial de base para la toma de decisiones en común. El catequismo y las misas son otros espacios de aprendizaje lingüístico y cultural, así como de los derechos humanos. Los esfuerzos crecientes de "concientización" de las masas campesinas que los catequistas bilingües llevan a cabo adquieren un carácter educativo, ya que su enseñanza no solo se aboca al estudio de la Biblia, sino que abarca también cursos en lenguas nativas sobre la historia de México y Chiapas, economía política, y comercio nacional (Benjamin, 2000, p. 437).

Las tres últimas décadas han visto crecer el número de organizaciones de derechos humanos que coadyuvan en los procesos de politización de las identidades. Fundada por los jesuitas a inicios de los años ochenta, Fomento Cultural y Educativo A. C. es una de las primeras asociaciones impulsora de la educación popular en la región selvática ${ }^{2}$, que incide en el campo de la educación indígena desde el sector asociativo y conjuga sus esfuerzos con Desarrollo Económico Social de los Mexicanos Indígenas (Desmi), una ONG cercana a la Diócesis y pionera desde 1969 en materia

2 La zona de intervención actual de Fomento Cultural y Educativo A. C. comprende 80 comunidades tseltales, zoques y ch'oles (noroeste de la Selva) de la Coordinadora de Organizaciones Sociales Indígenas Xi'nich, compuesta principalmente por el Comité de Defensa de la Libertad Indígena, y Tsoblej Yu'un Jwocoltic. 
de economía solidaria. En su conjunto, los actores de la sociedad civil facilitan de manera relativa la construcción social de las condiciones para la apropiación indígena de la defensa del derecho a una educación que sepa reactivar y aprovechar sus saberes, tradiciones y formas de organización propia.

\section{Nombramiento comunitario del educador campesino maya tseltal}

La construcción de las demandas de educación autónoma se sitúa en un espacio territorial en el cual tiene mucho sentido para las familias campesinas nombrar, evaluar y tal vez demitir de sus funciones de manera colectiva a los responsables de los cargos de distinta naturaleza en cada comunidad. Desde hace tres décadas, cuando la organización campesina Unión de Uniones empezó a introducir el tema de la escolarización en su agenda política, busca paliar los serios problemas de acceso a la educación primaria, sobre todo en los asentamientos menos poblados y más aislados ${ }^{3}$,

Antes del desarrollo de los programas del Conafe, las escuelas de las comunidades con menos de mil habitantes no ofrecían los seis grados de primaria, lo que obligaba a los niños a desplazarse y era factor de deserción y abandono escolar. En 1990, según los datos de la ARIC-UU, 1116 niños de las Cañadas de Ocosingo, de un total de 7044 de 6 a 15 años, no asistían a la escuela. Además, el $51 \%$ de la población de más de cinco años no sabía leer, y cerca de un tercio de aquellos entre los 6 y los 15 años no iban a la escuela en el segundo valle de Ocosingo (región Estrella), donde el $45 \%$ de su población indica no saber leer ni escribir (Leyva, 1995, p. 394). donde preexisten grandes carencias o casi inexistencia de servicios sociales en general. Además de comités de salud y de educación a nivel local, y de las comisiones regionales, la ARIC-UU extiende el mecanismo del nombramiento comunitario a nuevos puestos de "promotores", que no son profesionales de su área de acción. Mientras operaban "promotores de salud" (alópatas) en las Cañadas de Ocosingo desde años antes, los primeros "promotores de educación" (primaria) solo aparecieron en 1988 bajo una fórmula híbrida, resultado de la negociación entre la ARIC-UU y el Gobierno. Los actores involucrados generaron así un mecanismo de control local que facilitaba un mayor arraigo local del docente para extender la cobertura escolar. Su característica fundamental era el nombramiento comunitario del promotor de educación con un modo bastante similar a la designación de las autoridades indígenas en los cargos políticos y religiosos de los "servidores del pueblo" (Lomelí, 2002).

Esto implica la redefinición de la posición social del docente en el campo político y educativo tanto a nivel local como regional. El nombramiento comunitario del docente dio lugar a nuevos tipos de derechos, obligaciones y restricciones en la gestión local de las escuelas de los "maestros campesinos". Sin embargo, estos nuevos promotores educativos no pertenecían al cuerpo de funcionarios públicos y no eran sindicalizables. Tampoco fungían 
como titulares de un cargo tradicional de los pueblos tseltales y tsotsiles (Aguirre Beltrán, 1981), puesto que en contraparte de su servicio docente reciben una módica beca por parte del Estado.

En 1988 en un puñado de comunidades organizadas, los campesinos tseltales, designaron y ratificaron colectivamente a un joven, "kerem", oriundo de la localidad, para ocupar las funciones de "nopteswanej" (en tseltal, "el que enseña"). Se amplió el año siguiente en una treintena de ejidos y rancherías de las Cañadas de Ocosingo que no contaban con servicios educativos o donde se evidenciaban conflictos con los docentes enviados por la administración de la educación federalizada. Entre 1988 y 1994, el experimento híbrido, por su naturaleza institucional, se denominó Programa Alternativo de Educación Indígena, luego Programa de Educación Básica de la Selva y Programa de Educación Integral de las Cañadas de la Selva Lacandona (Peicasel); así se superaba de momento el número de escuelas comunitarias del Conafe en la región. Esta nueva modalidad estatal de educación comunitaria indígena se construyó así por medio de la cooperación estrecha entre la burocracia educativa del estado de Chiapas y la ARIC-UU y las coordinadoras del Peicasel, Marta Orantes y Teresa García ${ }^{4}$. Su control recaía en la Administración Pública, mientras que la organización campesina pasó de tener un rol de impulso a un rol indirecto de formación, supervisión y vigilancia de los asuntos escolares cotidianos, sin incidir mucho en la orientación política y pedagógica.

Sin embargo, el nuevo uso del nombramiento del educador por su propia comunidad de origen no garantizaba el carácter situado y endógeno de la producción de contenidos y métodos pedagógicos empleados en clase. Por otra parte, el impulso y el respaldo político de la ARIC-UU no implicaban del todo que la enseñanza impartida en el Peicasel contribuyera a una educación intercultural crítica que aportara a la politización de los contenidos curriculares destinados a la niñez. Es ambiguo además el carácter étnico de esta nueva propuesta, ya que no surgió de un real proceso participativo a nivel local e intercomunitario en la definición de las orientaciones pedagógicas de las escuelas.

Al igual que en toda la región durante los años ochenta, la comunidad de Hermenegildo Galeana tuvo dificultades con los

4 Ex miembros de un pequeño grupo izquierdista conocido como Unión del Pueblo, que trabajó de forma directa desde los años setenta hasta 1997 con las autoridades de la Unión de Ejidos Kiptik y la ARIC-UU. De 1988 a 1997, ellas formaron con Carmen Legorreta en el sector agrario un equipo de asesores influyentes. 
maestros enviados por la SEP que no cumplían con sus propias expectativas. Para suplir las deficiencias de la oferta escolar, los dirigentes locales organizados en la ARIC-UU propusieron la elección, en 1990, de un "educador comunitario": Joshua ${ }^{5}$, menor de edad, cuyo testimonio se presenta en adelante. Este nombramiento colectivo fue ratificado públicamente por medio de la asamblea y el consentimiento comunitario. De manera retrospectiva, Joshua considera que su nombramiento se debe mucho a su preparación escolar, no obstante modesta.

Seguí estudiando, estudiando, así que ya salió mi estudio, pues. En ese tiempo había una organización que se llamaba, ARIC Unión de Uniones; ya en esa reunión había delegados, era reunión de los delegados. También estaban en contra del gobierno, decían, pero quién sabe si era cierto, eso decían. Querían una educación de la comunidad, que se eligiera educador para que enseñe a los niños porque ya lo vieron que los maestros no enseñan bien. Se van y vienen $y$ casi no tienen interés en

Entrevista realizada en enero de 2007 en la cocina de su familia en presencia de sus hijos, en una comunidad tseltal ubicada en las tierras recuperadas de la antigua finca Santa Rita en el municipio Francisco Gómez. El nombre de Joshua corresponde al que este experimentado educador zapatista ha declarado para citarlo. los niños. Así que como no había más niños que sí tenían estudio, pues como antes no entraban creo en la escuela, como mis tres hermanos que casi no sabían leer. Y por eso decían, no pues, tú tienes que entrarle, nuestros papás te dan chance. Pues hay que aprovecharlo. $Y$ así que no me dejaban traer leña, así como traigo ahorita, no, así estaba yo de quince años todavía en la clase. Pero la comunidad vio que así ya teníamos nuestro estudio, pues ya nos nombraron como promotor de... ¡no! como educador comunitario; eso, de Peicasel. [...] cuando me eligieron para enseñar a los niños, se hizo una acta de compromiso que recibían las autoridades de la organización, por ejemplo presidente, tesorero, secretario; autoridades de la organización, ellos le daban todos los papeles, ellos los recibían. Por eso a veces ahí juntan a los delegados, ahí dicen cuál maestro está fallando, cuál maestro no está haciendo el trabajo, ahí se ve. 
Este testimonio ilustra el impulso decisivo dado al proyecto inicial de educación comunitaria por parte de los delegados de la ARIC en la región. Después de su nombramiento ratificado en asamblea, los "promotores de educación", llamados también "educadores comunitarios" y "maestros campesinos", fueron invitados a San Cristóbal para asistir a breves sesiones regulares de formación impartidas por el equipo de capacitadores reclutados por las coordinadoras del Peicasel. Según Teresa García, coordinadora del área pedagógica del programa, entrevistada en su oficina del World Trade Center de la Ciudad de México (febrero, 2007),

[...] primero empezaron cursos de capacitación, cuidando que se pudieran reproducir con sus niños bajo programas muy específicos, o sea, yo lo que decía es que tanto el cuaderno como el programa del maestro, como todo lo que el maestro iba a trabajar día con día, lo teníamos que tener muy dirigido. Entonces hicimos un enorme esfuerzo durante varios años para hacer una currícula de educación para indígenas, para niños tseltales, étnica.

Más allá de estos valiosos esfuerzos para la elaboración de algunos materiales didácticos de lectoescritura en tseltal que complementan los manuales y los programas de la SEP, ihasta qué punto se puede hablar de una propuesta "étnica" cuando está elaborada "para indígenas" y no por ellos mismos en un proceso participativo, garantizando una enseñanza de acuerdo al contexto y las aspiraciones sociales? Además, la cuestión del carácter propio y endógeno es relevante si se consideran las rupturas y las continuidades en la realidad escolar regional, en función de los objetivos, contenidos, métodos y alcances que se vislumbren y se desarrollen. En cuanto a la figura docente, los nuevos "maestros campesinos" tienen una posición social subordinada en el campo educativo de las Cañadas, a diferencia de los "maestros federales", que aparecen como los auténticos profesionales de la docencia. El siguiente relato de Teresa García muestra cómo el uso de representaciones teatrales satíricas (sociodramas) comprueba la lógica de ruptura franca que pretende instituir la ARIC-UU con la representación social del docente en la comunidad.

Poníamos al típico maestro de la SEP, perdón por la comparación pero así lo hacíamos en obras de teatro, 
poníamos al típico maestro de la SEP como el más malo. Entonces había que reírse y burlarse de todo lo que hacía, entonces todo lo que hacía era tomar, llegar tarde, pegarles a los niños, no estar, faltas de ortografía o sea ese era el prototipo del maestro de la SEP. En cambio el maestro comunitario era el más correcto, con mejor presentación, el que tocaba temprano el cuerno, el que leía perfectamente, el que tenía una excelente ortografía, el que trataba con mucho cariño y le [sic] daba muy buen trato a los niños, el que siempre estaba leyendo y orientando, entonces era muy curioso, muy seguido entonces en los festivales poníamos al maestro de la SEP y al maestro comunitario, al bueno $y$ al malo.

En la construcción de las demandas educativas autonómicas, esta dicotomía sugerida por la crítica de los comportamientos "típicos" de los maestros bilingües corresponde a la politización del nombramiento comunitario en la medida en que puede aparecer como una garantía del compromiso del "maestro campesino" con la educación en su propia localidad de origen. No obstante, la aparición de una suerte de cargo de promotor de educación comunitaria no determina de manera unívoca que las autoridades y bases indígenas hagan suya la demanda de poner la escuela como herramienta de transmisión de las normas y los valores asumidos como culturalmente propios y políticamente sensibles.

\section{Concesión del Estado y alternativa campesina indígena en vísperas del levantamiento armado}

Para extender la cobertura escolar de niños tseltales en pequeñas localidades de la Selva Lacandona, el Estado concede prerrogativas en materia educativa a la principal organización campesina e indígena del sur mexicano. De manera inédita en la región antes del levantamiento armado de 1994, las autoridades educativas y el Gobierno del estado de Chiapas confirieron a los responsables de la red de comunidades organizadas en la ARIC-UU la posibilidad de designar, capacitar y supervisar a educadores comunitarios propios. Los recursos federales de la Secretaría de Desarrollo Social del gobierno de Carlos Salinas de Gortari y del Banco Mundial durante dos de los primeros años de su gestión permitieron financiar la capacitación de 400 promotores de educación por 
un equipo de formadores ladinos reclutados según los criterios de las coordinadoras. Según los datos de la Secretaría de Educación del Gobierno de Chiapas, el Peicasel escolarizó 960 alumnos entre 1989 y 1990 y alcanzó más de 7000 matrículas cuando surgió el levantamiento zapatista.

En la práctica cotidiana, los "maestros campesinos" reproducían en gran parte los métodos y contenidos pedagógicos que conocían de su infancia, y a los cuales agregaban ciertos elementos asimilados a través de su experiencia en los cursos de capacitación recibidos en español en San Cristóbal. Este programa compensatorio no fungió de manera radical como modelo comunitario propicio a la investigación local y al refuerzo directo de la enseñanza bilingüe e intercultural, pero contribuyó a la castellanización de los niños y a la apropiación de la gestión un poco más autónoma de la escuela por parte de la organización comunitaria (Baronnet, 2012).

A pesar de haber sido adoptado por alrededor de cien comunidades en total, la modalidad Peicasel no ha sido una alternativa para que las asambleas indígenas renuncien a recibir a maestros foráneos y a reclamar una educación bilingüe e intercultural. Entonces, la aparición de los "maestros campesinos" responde a una lógica circunstancial que busca menores costos, riesgos económicos y políticos para el Estado, y se presenta como un programa de ajuste coyuntural y transitorio hacia su integración plena a la administración educativa federal. Por su lado, la ARIC-UU considera la oportunidad de nuevos espacios de control político indígena en las Cañadas. En palabras de Teresa García, la escuela debe estar controlada por los propios comuneros.

Un procedimiento que estábamos siguiendo con el PEICASEL, era de que fuera la comunidad quien se apropiara del trabajo del maestro, ese era el ideal pues. Que fuera la propia comunidad quien controlara al maestro, lo supervisara y que fuera el maestro comunitario quien tuviera que rendirle a la comunidad la información, esa era un poco la mecánica que nosotros queríamos impulsar [...]. Nosotros decíamos que debía de haber mucho control de la comunidad hacia su maestro y que fuera el maestro quien tuviera que rendir a los padres de familia y a la comunidad el reporte de cómo van los hijos. Que sintiera la comunidad como su jefe, que fuera su 
comunidad la que tuviera el control del maestro. Había que hacer asambleas con padres de familia, explicarles, plantear los procedimientos para que el maestro cada mes pudiera rendirle a los padres de familia.

A pesar de su contribución económica, la participación social en las comunidades para la ejecución de este programa alternativo fue limitada. La gestión de la mayor parte de la contribución financiera quedó en manos de sus ejecutoras principales, encargadas de la coordinación administrativa y pedagógica. A cambio de mayor autonomía en el nombramiento y la vigilancia del docente, se invitaba a las comunidades a contribuir con alimentación y vivienda, así como con la construcción, el equipamiento y el mantenimiento de las modestas aulas escolares ${ }^{6}$. Con el impacto del ajuste neoliberal sobre las políticas étnicas en Latinoamérica (Gros, 2000), los gastos educativos del Estado se redujeron a medida que la construcción de las infraestructuras y los mobiliarios escolares se realizaba gracias a la cooperación material y la tradición de trabajo gratuito. La entrada de las escuelas comunitarias federales y estatales en las Cañadas entre mediados de los

6 Las paredes están hechas de tablas de madera y con escasas ventanas en general. Los techos son de paja, palma o guano, y progresivamente cubiertos por láminas sintéticas y galvanizadas. años ochenta y noventa explotó la contribución directa y sistemática de la organización comunal de los ejidatarios y pequeños rancheros para obtener con menores costos públicos la construcción rápida de edificios escolares con sus propios medios. Por ende, los modelos de la arquitectura indígena en la Selva se manifiestan en las aulas escolares, que son bastante similares a las modestas casas particulares y los espacios comunes como la capilla.

Joshua es, tal vez, el único promotor zapatista de educación en la región que fue maestro campesino antes de 1994. Por consideraciones de orden político, algunas comunidades y jóvenes educadores tseltales, como Joshua, abandonaron voluntariamente el programa de educación híbrido y administrado por los asesores y los dirigentes de la ARIC-UU.

Me salí en 1993, la comunidad no me sacó, sino así solo. Una vez tuvimos reunión allá en el Suschila, Ilegaron las autoridades del gobierno y también de la organización [ARIC], dijeron ahora aquí van a decidir, como también los maestros. Todos los promotores de la educación llegaron ahí y nos dijeron: "ahora aquí hay dos caminos, el que quiera ir aquí está bien que diga claro ahorita 
porque los zapatistas también, el que se va de zapatista no vamos a permitir a ser maestro de nuestra organización". "Namás si va a estar con nosotros adelante, en estos tiempos se va a aumentar pues el salario". Por ejemplo, antes estábamos ganando 600 ahora el que está ganando 600 va a llegar a 1500-1200. Ora vayan en grupo los maestros nos van a decir: va a estar con nosotros todos está bien, o se van a ir con zapatistas orita van a decidir, decían las autoridades. [...] como no dijeron nada de lo que yo dije en la asamblea pues ya, ni modo, si nos desprecian, pues no voy a estar con ustedes, me voy con los zapatistas, también estoy viendo la necesidad de la tierra todo eso, pues, con poco dinero no puedo vivir, no puedo vivir con poco dinero yo pienso porque tengo familia y tengo hijos y tengo que salir en esa organización donde estamos, me voy con los zapatistas. Así sería más seguro. Bueno, pues ni modo, si él se decidió pues ya que se vaya dijeron y ya no me permitieron entrar a la junta ya me regreso en mi casa, sí, así fue cuando me salí de esa organización, eso fue en 93. (Entrevista, enero de 2007)

A pesar de ofrecer un aumento considerable de la beca de los maestros campesinos, las coordinadoras no lograron retener a los jóvenes zapatistas dentro de este programa de educación comunitaria. Perceptible antes de 1994, esta división en el Peicasel se dio entre campesinos indígenas zapatistas y no zapatistas y prefiguró la descomposición posterior de la ARIC. Además, estaban sentadas las bases de las lógicas de construcción comunitaria del autogobierno educativo: los actores de los pueblos estaban empezando a demostrar que la educación puede ser un elemento constitutivo de sus luchas ubicadas en los márgenes de la acción del Estado. Cuando Joshua afirma "me voy con los zapatistas" se refiere a una ruptura política con la política gubernamental, poniendo en relieve la bifurcación entre el proyecto estatal y la gestación de un proyecto "muy otro" de educación autónoma, verdaderamente intercultural y crítico a nivel pedagógico en su dimensión pragmática. 


\section{Educación autónoma y participación en la escuela zapatista}

Al final de la última década del siglo XX se cristalizaron las demandas indígenas en torno a una mayor autonomía en la gestión política de las escuelas de las regiones bajo influencia zapatista, es decir principalmente en los valles de las "tierras recuperadas" a los grandes propietarios agrarios. La creación de los municipios autónomos zapatistas en diciembre de 1994 coincidió con el inicio de una fase de experimentación en cuanto a la atención educativa de nivel de primaria en distintos bastiones zapatistas. En el caso de Joshua, la continuidad del trabajo de educador comunitario recibió el apoyo de "campamentistas" solidarios, es decir observadores de derechos humanos que servían de protección ante las agresiones militares y paramilitares, y quienes permanecían de manera breve y esporádica sin sustituir a los jóvenes educadores comunitarios y los profesores indígenas que aprovecharon la coyuntura para desertar de las escuelas de la zona en conflicto.

Los responsables indígenas del EZLN se preocupan asimismo por el tipo de contenido de la educación dirigida a los hijos de las bases de apoyo y lo que tiene que cambiar con relación al sistema educativo estatal. Para Doroteo (Escuelita zapatista, 2013, p. 4), ex integrante de la Junta de Buen Gobierno de
La Realidad, del municipio Libertad de los Pueblos Mayas, "nos vimos obligados a empezar nuestra propia educación aunque en algunos pueblos ya de por sí lo estaban haciendo. Para formar la educación autónoma teníamos que pensar si se daban los mismos planes de estudio de la SEP o cambiábamos, decidimos cambiar".

La educación autónoma en nuestra zona empezó desde 1997, en ese tiempo estaba funcionando la asociación de municipios. En aquel entonces se empezó a pensar cómo hacer nuestra educación porque allá en nuestra zona hubo un problema con los maestros del sistema de la SEP (Secretaría de Educación Pública), después de 1994 empezaron a tener muchos problemas con los pueblos. Empezaron unos a aparecer como espías, otros empezaron a usar el ejército para poder transportar sus útiles escolares, muchas cosas se dieron con ellos, entonces se decidió suspender sus entradas a nuestra zona. (Doroteo, en Escuelita zapatista, 2013)

El repudio al maestro enviado por la SEP forma parte de la justificación de la necesidad de hacer planes de estudios propios y realizar consultas 
sistemáticas "para que los padres de familia vieran qué otras cosas necesitaban ellos que se aprendieran en la escuela autónoma" (Doroteo, 2013). La propuesta curricular flexible que se extiende después a otras regiones autónomas consiste en dividir las actividades de aprendizaje en cinco áreas de conocimiento: "Lenguas", "Historia", "Matemáticas", "Vida y medio ambiente" e "Integración", que corresponde a "todas las cosas que eran necesarias estudiar y que no cabían en ninguna de las demás áreas tenían que caber ahí, por ejemplo el estudio de nuestras 13 demandas (techo, tierra, trabajo, salud, alimentación, educación, independencia, democracia, libertad, justicia, cultura, información y paz)" (Doroteo, 2013). El proyecto autonómico de educación zapatista funciona en realidad como una escuela de formación de cuadros y bases sociales comprometidos con el movimiento en el cual interactúan en la cultura política local, puesto que se aboca a la enseñanza plurilingüe de la lectoescritura y aritmética básica, en articulación con contenidos de aprendizaje basados en las demandas de su plataforma de lucha y una visión de la historia de "los de abajo y a la izquierda", es decir la historia de las propias comunidades y luchas sociales.

En el verano del año 2001, después de meses de consulta con sus bases y autoridades, los responsables del municipio autónomo que lleva el nombre del revolucionario libertario Ricardo Flores Magón elaboraron en la Selva Lacandona un documento -originalmente escrito en lengua tseltal- considerado directriz de lo que a su manera plantean como "educación verdadera". Sus objetivos y contenidos se originan en la experiencia histórica en su relación con el sistema educativo nacional, el cual es cuestionado y rechazado por considerar que no tiene en cuenta los valores, las culturas, las lenguas y las historias de los pueblos originarios de México y América. Como práctica democrática del "mandar obedeciendo", las propuestas educativas en sus contenidos y maneras de hacer surgen del consenso, la reflexión y la experiencia. Se llega así a la conclusión de que una educación verdadera emerge de las palabras y los conocimientos en los que todos los sujetos, en colectivo, deben "comenzar a aprender con los niños, mujeres, hombres y ancianos para que así vamos a lograr nuestra lucha" (Municipio Autónomo en Rebeldía "Ricardo Flores Magón", 2001). En este sentido, la enseñanza impartida por los y las docentes comunitarios denominados "promotores y promotoras de educación autónoma" está orientada hacia fines prácticos bien marcados, es decir: 
Enseñarnos a resolver el problema del pueblo. Vamos a saber siempre para qué sirven las cosas que vemos, y así vamos a hacer nuestro propio camino para resolver nuestras demandas y nuestros promotores poco a poco apoyan a su comunidad y la comunidad apoya a sus promotores, y así va a respetar y valorar la educación autónoma, y así nos hacemos ejemplo para otras organizaciones. (Municipio Autónomo en Rebeldía Ricardo Flores Magón, 2001)

Simbolizando fuentes éticas de inspiración por su ejemplaridad percibida más allá de Chiapas y de México, los Concejos Autónomos de los municipios rebeldes que componen cada una de las regiones de los cinco "Caracoles" creados en agosto de 2003 se encuentran actuando como representantes de quienes impulsan y coordinan los esfuerzos militantes en torno a la formación de una política comunal de educación. Los campesinos mayas participan colectivamente en esta de manera que incidan en los procesos de decisión y de gestión de los asuntos escolares. Los miembros en turno de los Concejos monitorean las obras y los proyectos comunitarios en una microrregión. En vez de recibir salarios, tanto las autoridades autónomas como los promotores de educación reciben una contribución de los varones de la aldea para colaborar con la alimentación de su familia y para mantener su parcela de cultivos de frijol y maíz principalmente.

Los miembros de los pueblos originarios que sostienen al movimiento zapatista se reconocen e identifican como comunidades autónomas que se encargan de conducir los proyectos municipales de "educación verdadera". Ello contribuye a enorgullecer a los propios portadores de las identidades zapatistas, mayas y campesinas que se ven reflejadas en las pedagogías puestas en práctica. Coincidiendo con el análisis de Horacio Gómez Lara, quien fuese antropólogo de origen tsotsil, las escuelas zapatistas tienen objetivos específicos como la reproducción del movimiento, pero no alcanzan a suplantar la educación tradicional indígena, que ocurre en el hogar, la milpa o la montaña, en la cual "se aprenden la cosmovisión, la lengua, y se inculcan las formas de organización religiosa, política, económica, etc., con la participación de los agentes y sus instituciones, familia y comunidad" (Gómez Lara, 2013, p. 107).

Distintos materiales didácticos elaborados de manera colectiva y horizontal han nacido de los equipos de promotores de "educación verdadera". A mediados de la década de los años 2000, se confeccionaron manuales de lectoescritura en distintas variantes del tseltal, tsotsil y tojolabal en el Caracol de Morelia, 
mientras en el Caracol de Roberto Barrios se realizaron folletos como el titulado Por qué peleó Zapata. Los productos didácticos y las prácticas pedagógicas de los educadores de los municipios autónomos muestran su interés por una pedagogía crítica, activa o constructivista, popular y decolonial, orientada a aprender a vivir la autonomía, conocer y hacer valer sus derechos, defender los recursos estratégicos y resolver problemas de fondo, como los vinculados a la subsistencia alimentaria en la vida cotidiana, como lo ilustran las siguientes palabras de Cristóbal, proveniente del Caracol de Roberto Barrios, en el marco del Primer Encuentro de los Pueblos Zapatistas con los Pueblos del Mundo (diciembre, 2006):

Desde que inició el proyecto de la educación, hasta ahora hemos empezado a avanzar poco a poco a resolver la demanda de alimentación que es ahí donde toca con esta actividad. $Y$ otra de las actividades que realizamos es la práctica de los proyectos productivos. Consiste en que cada escuela, el promotor junto con el comité local, que es la autoridad educativa dentro de cada comunidad, se ponen de acuerdo, discuten, qué proyectos van a realizar, ya sea crianza de pollo, de borrego de cerdo y así, este trabajo es ahí donde también trabajan un poquito, aprenden y trabajan los niños [...]. También, dentro de las escuelas autónomas participan los promotores de agroecología, en este caso cuando estamos hablando en la práctica de los huertos escolares, y también participan los promotores de salud que también dan pláticas, campañas de higiene, entre otras cosas.

La participación de un conjunto amplio de actores comunitarios en la educación autónoma, desde la asamblea hasta el aula, fortalece la naturaleza integral del aprendizaje esperado por los educadores y de las expectativas de las familias. Si bien los promotores de salud, de agroecología o de comunicación coadyuvan en las tareas pedagógicas, es interesante notar la participación a veces muy activa de los abuelos y ancianos de las aldeas, complementaria a la de los padres de alumnos, a través de formas de intervención política y pedagógica en las prácticas asamblearias e incluso directamente en el aula. Las escuelas zapatistas dependen, entonces, por un lado de las dinámicas de asambleas comunitarias, coordinadas por los comités de educación que cumplen la función de evaluación y vigilancia directa, y por otro del desempeño de los promotores que, a su vez, se 
articulan con los coordinadores de proyectos (educación, salud, producción, etc.) representados en los municipios que conforman las Juntas de Buen Gobierno con sede en cada uno de los cinco Caracoles (Núñez Patiño, 2013, p. 90). Los jóvenes zapatistas se forman además "para que sus saberes, valores y metas culturales sean reconocidos a partir de la lucha por su derecho a la autodeterminación, solamente ejercida en una transformación de las relaciones que trasciendan la actual estructura de poder del Estado Nacional" (p. 91). En este sentido, las aspiraciones zapatistas de control comunitario de la educación pasan por la referencia directa en la escuela a los valores específicos que impulsa el propio movimiento.

El objetivo de la educación zapatista es que fortalezca nuestra cultura, lengua, educación en la propia familia, el colectivismo, la unidad, la disciplina, el compañerismo, aprender a resolver la necesidad de nuestros pueblos, el respeto a nuestras culturas, a defendernos con dignidad, nos enseñe a trabajar, que una el trabajo $y$ la vida, a nuestra madre naturaleza [...]. El objetivo de nuestra educación es que todos aprendan y entiendan la situación en que vivimos. Y esto no lo dudamos porque nuestro sueño lo tenemos que hacer realidad, cueste lo que cueste. (Declaración del Comandante Insurgente Zebedeo, Segundo Encuentro de los Pueblos Zapatistas con los Pueblos del Mundo, julio de 2007)

Al aprovechar los valores, los conocimientos y las identidades político-culturales en la arena educativa, las asambleas comunales y las instancias internas de deliberación en las comunidades autónomas de Chiapas representan los agentes de la transformación de la escuela y una cierta garantía de legitimidad para la interculturalización del currículo. En la construcción de las demandas y las prácticas educativas se delegan y controlan los poderes asumidos por el educador a partir de un cargo resignificado y adquirido con base en el reconocimiento consensuado de su capacidad, prestigio y trayectoria personal en la vida política cotidiana local (Baronnet, 2012). El trabajo docente no solo se legitima por la mera disponibilidad y entrega como militante a favor del proyecto político comunal, sino que se enorgullece también al recibir el reconocimiento de las autoridades municipales y regionales, así como de las redes de solidaridad nacional e internacional que han contribuido en el 
pasado a la capacitación de los educadores y la construcción de infraestructuras escolares.

Además, un elemento fundamental que está en juego también en la construcción de las demandas autonómicas en educación se refiere a la toma de conciencia de las especificidades identitarias y culturales situadas en el imaginario regional en relación con la cultura nacional occidental. De acuerdo con Gutiérrez Narváez (2011, p. 264), el proceso de construcción social de la escuela está "ciertamente lleno de obstáculos y contradicciones pero es mucho más significativo para los sujetos indígenas", quienes comparten "valores como la cooperación, el trabajo colectivo, la reciprocidad, la solidaridad, la organización horizontal, la participación activa, la revaloración de los agentes, conocimientos y significados indígenas". A pesar de dificultades ligadas al contexto de guerra integral de desgaste que mina los apoyos al EZLN y la escasez de recursos materiales y técnicos, la construcción social de las demandas de autonomía educativa se concretiza en la participación en alternativas escolares. Estas representan una manera de reflejar y reproducir las identidades indígenas, campesinas y zapatistas en los contenidos escolares, sin dejar de considerar que el ejercicio comunal de estos derechos colectivos contribuye a fortalecer el orgullo y la dignidad de pertenecer a pueblos oprimidos en búsqueda de liberarse del yugo neocolonial que recobra hoy la forma del sistema capitalista al cual se oponen firmemente a partir de estrategias regionales de desarrollo autosostenible.

\section{Conclusiones}

En las dos décadas que preceden el surgimiento de las escuelas zapatistas, la demanda de educación crítica e intercultural se construye en relación directa con la autoorganización campesina y religiosa en los pueblos y rancherías de Chiapas. A través de sus diversas expresiones, el movimiento social indígena viene planteando nuevas alternativas de vinculación con el Estado, con un modelo de ciudadanía multicultural que se expresa en el campo de la autonomía y la educación intercultural (Stavenhagen, 2013, pp. 45-46), con el ejercicio de los derechos colectivos como espacio de formación política para el "buen gobierno". A raíz de procesos de politización de las identidades étnicas, las Cañadas constituyen un escenario amplio para la construcción de demandas y de proyectos tseltales que giran 
hacia "otra educación", "verdade$\mathrm{ra}^{\prime \prime}$ y autónoma, sentando asimismo las bases decoloniales para una pedagogía intercultural crítica. En este sentido, la construcción de la demanda educativa corresponde a lo que Walsh (2010, p. 93) llama:

[...] una praxis pedagógica crítica, intercultural y de-colonial que pretende pensar no solo "desde" las luchas de los pueblos históricamente subalternizados, sino también "con" sujetos, conocimientos y modos distintos de estar, ser y vivir, dando un giro a la uninacionalidad y monoculturalidad fundantes de la empresa educativa.

Considerando esta praxis en los contextos regionales de las acciones colectivas y los movimientos sociales, la resignificación de la función social atribuida a la educación escolar en la vida comunal corresponde a experiencias descolonizadoras notorias, que pueden considerarse como relevantes para la emergencia de una interculturalidad crítica en la educación de América Latina (Walsh, 2010; Medina \& Baronnet, 2013).

En este sentido la educación intercultural crítica y descolonizante se edifica sobre las bases de una lucha social por la reconstitución de los pueblos que hoy tomó explícitamente el camino de las autonomías políticas. La interculturalidad crítica en educación autónoma se construye social e históricamente en el contexto estructurado y estructurante del autogobierno intercomunitario, evitando dejar la conducción de los asuntos educativos en manos exclusivamente del Estado y sus agentes. La cuestión políticocultural del quehacer educativo depende entonces de las condiciones autonómicas, lo que implica que la autodeterminación política se vuelve una condición necesaria para el ejercicio de los derechos a una educación intercultural.

Contra viento y marea, los pueblos zapatistas hoy son quienes participan de manera directa en los procesos de decisión sobre la pertinencia cultural de las formas escolares y los contenidos curriculares, apropiándose de la escuela como instancia socializadora para enseñar y aprender a "mandar obedeciendo". La lucha por la dignidad de las culturas indígenas desde la esfera educativa alimenta la participación activa de los jóvenes y adultos en el marco de una democracia comunitaria. Este anhelo democrático y libertario se erige en una condición ineludible para que de su intervención emerjan proyectos autonómicos de naturaleza descolonizante, que representan desde luego fuentes formidables de inspiración en otros contextos de lucha social, para elaborar estrategias de construcción de demandas educativas nuevas. 


\section{Referencias bibliográficas}

Aguirre Beltrán, G. (1981). Formas de gobierno indígena. MéxiCO: INI.

Baronnet, B. (2012). Autonomía y educación indígena. Las escuelas zapatistas de la Selva Lacandona en Chiapas, México. Quito: Abya-Yala.

Baronnet, B. (2013). Desafiando a la política del Estado: las estrategias educativas de los pueblos originarios en Colombia y México. Revista Pueblos y Fronteras digital, 8 (15),126-156.

Benjamin, T. (2000). A time of reconquest: History, the Maya revival, and the Zapatista rebellion in Chiapas. The American Historical Review, 105, 417-450.

Bobrow-Strain, A. (2007). Intimate enemies: Landowners, power, and violence in Chiapas. North Carolina: Duke University Press, Durham.

Cardoso de Oliveira, R. (1990). La politización de la identidad y el movimiento indígena. En, J. Alcina Franch (coord.). Indianismo e indigenismo en América (pp. 145-161). Madrid: Alianza.

García de León, A. (2002). Fronteras interiores, Chiapas: una modernidad particular. México: Océano.

Gilly, A., Subcomandante Marcos y Ginzburg, C. (1995). Discusión sobre la historia. México: Taurus.

Gómez Lara, H. (2013). ¿Escolarizados para qué? La difícil marcha atrás: escuela, descampesinización y desestructuración comunitaria. En, G. Ascencio (coord.). Teoría y práctica de la educación intercultural en Chiapas (pp. 103-125). México: UNAM.

Gros, Ch. (2000). Políticas de la etnicidad: identidad, Estado y modernidad. Bogotá: Instituto Colombiano de Antropología e Historia.

Gutiérrez Narváez, R. (2011). Dos proyectos de sociedad en Los Altos de Chiapas. Escuelas secundarias oficial y autónoma entre los tsotsiles de San Andrés. En: B. Baronnet, M. Mora Bayo y R. Stahler-Sholk. Luchas 'muy otras'. Zapatismo y autonomía en las comunidades indígenas de Chiapas (pp. 267-294). México: UAM, Ciesas, Unach.

Lewis, Stephen E. (2005). The Ambivalent Revolution: Forging State and Nation in Chiapas, 1910-1945. Albuquerque: University of New Mexico Press. 
Leyva Solano, X. (1995). Catequistas, misioneros y tradiciones. En: J. P. Viqueira y M. H. Ruz (coords.). Chiapas, los rumbos de otra historia (pp. 375-405). México, UNAM, Ciesas, Cemca, UdeG.

Lomelí, A. (2002). Los servidores de nuestros pueblos. Syu'el jtuuneletik ta jlumaltik. Tuxtla Gutiérrez: Coneculta.

Maldonado, B. (2002). Los indios en el aula. Dinámica de dominación y resistencia en Oaxaca. México: INAH.

Medina Melgarejo, P. y Baronnet, B. (2013). Movimientos decoloniales en América Latina: un balance necesario desde las pedagogías interculturales emergentes en México. En: María Bertely, Gunther Dietz y Guadalupe Díaz Tepepa (coords.). Multiculturalismo y educación, 2002-2011 (pp. 415-448). México: Comie/Anuies.

Núñez Patiño, K. (2013). Conocimiento, conciencia y práctica: aprendizajes en la educación autónoma zapatista. Argumentos, 73, (26), 81-92.

Orozco López, E. (2014). La organización Sociedad Civil "Las Abejas". Procesos de lucha, resistencia y educación indígena. Tesis de doctorado en Ciencias Sociales, Cesmeca-Unicach. San Cristóbal de Las Casas.
Rockwell, E. (1997), Cursos comunitarios: una primera alternativa para el medio rural. Revista Colombiana de Educación, 34, 85-106.

Rockwell, E. (2006). Historias contrastantes de la apropiación de la escritura en dos pueblos indios: los nahuas de Tlaxcala y los tseltales de Chiapas. En: Bertely, M. (coord.). Historias, saberes indigenas y nuevas etnicidades en la escuela (pp. 35-68). México: Ciesas.

Sarmiento Silva, S. \& Mejía Piñeros, C. (1987). La lucha indígena: un reto a la ortodoxia. México: Siglo XXI.

Stavenhagen, R. (2013). La política indigenista del Estado mexicano y los pueblos indígenas en el siglo XX. En, B. Baronnet \& M. Tapia (coords.). Educación e interculturalidad. Política y políticas (pp. 23-48). Cuernavaca: CRIM-UNAM.

Walsh, C. (2010). Interculturalidad crítica y educación intercultural. En, J. Viaña, L. Tapia y C. Walsh. Construyendo interculturalidad crítica (pp. 75-96). La Paz.: III-CAB.

\section{Recursos electrónicos}

Congreso Indígena, Ponencias y acuerdos, 13-14-15 de octubre de 1974. Recuperado de: www.cedoz.org. 